\title{
Agony at a Distance : Investigating Digital Witnessing on YouTube
}

\section{Sumiala, Johanna}

Springer

2019

Sumiala , J 2019 , Agony at a Distance : Investigating Digital Witnessing on YouTube . in T Eberwein , M Karmasin , F Krotz \& M Rath (eds), Responsibility and Resistance : Ethics in Mediatized Worlds . Ethik in mediatisierten Welten , Springer , pp. 131-145 . https://doi.org/10.1007/978-3-658-2621

http://hdl.handle.net/10138/333072

https://doi.org/10.1007/978-3-658-26212-9_8

acceptedVersion

Downloaded from Helda, University of Helsinki institutional repository.

This is an electronic reprint of the original article.

This reprint may differ from the original in pagination and typographic detail.

Please cite the original version. 


\section{Agony at a Distance \\ Investigating Digital Witnessing on YouTube}

\section{Summary}

In this chapter I analyze the media ethics of digital witnessing by elaborating the theoretical work on media witnessing carried out by media scholars such as John Durham Peters, John Ellis, Paul Frosh, Amit Pinchevski and Lilie Chouliaraki. I focus on digital witnessing on YouTube and analyze in detail one particular YouTube video clip. This video clip entitled For our son was made by the father of the Finnish school shooter and was posted on YouTube in 2008. The empirical analysis of digital witnessing was based on the thematic close reading of the media material and was structured around the three key elements in media witnessing: (i) ordinary people as witnessing agents on YouTube; (ii) YouTube videos as a representation of witnessing; and (iii) viewers as bearing witness. In conclusion, I discuss the ideas of responsibility as agony and the sense of proper distance as necessary conditions for the communicative action of bearing digital witness.

\section{Key words:}

digital witnessing, YouTube, school shootings, intimacy, distant suffering, agony 


\section{Introduction}

Since 9/11 in 2001, the interplay between media events and witnessing in the media has become of great interest in the scholarship of media ethics (e.g., Ellis, 2009; Frosh \& Pinchevski, 2009; Katz \& Liebes, 2007; Liebes \& Blondheim, 2005; Peters, 2009a; Rothenbuhler, 2010; Scannell, 2001). What is at stake is the issue of the changing conditions of media witnessing and the ubiquity of digital witnessing. The concept of ubiquity refers here to the circumstance of the media-saturation of witnessing embedded in the expansion of digital media technologies, the global circulation of media events, and practices of amateur and vernacular participation (see, e.g., Jenkins, 2006). As Frosh and Pinchevski (2009, p. 2,8) point out, contemporary developments in media technologies and audience participation mobile phones, tweets on Twitter, cell-phone-based cameras, Facebook and YouTube make media witnessing an extremely complex issue. We live in a world in which any act of posting, uploading, and disseminating testimonies implies an unlimited potential for circulation, remediation and sharing of media witnessing (see Sumiala \& Tikka, 2011).

Consequently, complex relationships emerge between different agents acting as digital witnesses. Professional media institutions, such as television, have traditionally held a dominant position in orchestrating witnessing in media. The audio-visual mass media in particular have typically broadcast multiple forms of media witnessing in a variety of genres, ranging from journalistic forms of reporting, eyewitness news, the recollections of historical events, public hearings, and talk shows. As a result, audiences in modern societies watch crimes, crises and 
catastrophes impact upon individuals with whom the viewers have no physical contact or who they do not know personally (Thomas, 2009, p. 89).

However, what has changed after the emergence of the Internet is the rise of ordinary people as active agents of digital witnessing. With this new dynamic, categories of production, representation and reception of media witnessing are changing. Neologisms like "prosumer" and "produsage" (producer + consumer, user or usage) refer to the conditions under which ordinary people take more visible roles as both the addressees and producers of digital witnessing (cf. Sumiala \& Tikka, 2011). In this emergent renegotiation of categories of witnessing (who, what and to whom) - carried out and perceived in, by and through the complex web of different mediated structures - the practices and conventions of digital witnessing are becoming culturally significant on a new scale that demands further research in media and communication scholarship (Frosh \& Pinchevski, 2009, p. 12).

In this chapter I work from the premise that digital witnessing in the present age is to be approached as a constant struggle between different media-related structures, practices and conventions that seem to be contingent upon the specific event witnessed (see Ashuri \& Pinchevski, 2009, p. 133). By examining YouTube as an audio-visual digital technology, I want to discuss a new modality of perception in digital witnessing (cf. Ellis, 2009). I complement my theoretical analysis on witnessing in social networks with an empirical case study from YouTube: witnessing the Jokela school shootings in Finland, which took place in 2007 (see, e.g., Sumiala \& Tikka, 2011; Sumiala \& Tikka, 2010).

I focus on one particular video clip, entitled For our son, which is a video made by the father of the Jokela school shooter. The video was uploaded onto YouTube in 2008, about a year after Pekka-Eric Auvinen (the son) had massacred 
nine people (including the principal, the school nurse and six students, some of them his classmates, and himself) at the Jokela School Centre in Tuusula, in the south of Finland. My analysis of digital witnessing in this particular video clip is structured around the three key elements: (i) ordinary people as witnessing agents on YouTube, i.e., the father who bears witness to the death of his son, (ii) YouTube videos as a representation of witnessing, and (iii) the viewer, who bears witness by watching the video For our son. I will start with some theoretical reflections on media witnessing and social networks, namely YouTube and then move to my case study of For our son. Finally, I will draw some preliminary conclusions on digital witnessing on YouTube and discuss the ideas of responsibility as agony and the sense of proper distance as necessary conditions for digital witnessing (Chouliaraki, 2011, 2010).

\section{Media witnessing}

Put simply, media witnessing is the witnessing performed in, by and through the media. It requires an agent who witnesses, a witnessing representation and an audience that either or both receives and accepts the witness. Moreover, media witnessing changes the condition of witnessing by reformulating the category of "being there". Media witnessing is typically acted out in a systematic and on-going reporting of the experiences and realities of distant others to mass audiences or masses of different types of audiences (Frosh \& Pinchevski, 2009, p. 1). For Peters (2009a, p. 23) and many others, media witnessing is characteristically a mode and practice of communication. In other words, it entails putting an experience into language (or image, for that matter) for the benefit of those who were not there. Media witnessing is about seeing and saying and it is deeply embedded in questions regarding truth and experience, presence and absence, death and pain, and the 
trustworthiness of perception. Furthermore, media witnessing also includes an element of responsibility. To witness someone's suffering in the media has a moral implication to it. It puts a spectator under a moral obligation towards the one who is suffering (cf. Ong, 2014).

Ashuri and Pinchevski (2009, p. 133-135) distinguish two key approaches to theorizing media witnessing: 1) the implicated witness and 2) the vicarious witness. The notion of an implicated witness emphasizes the distinction between witnessing agents and mere spectators, between those who were there and the ones who "only" watched the event through the media. In this approach, one qualifies as a witnessing agent predominantly by virtue of being present. This is in line with Peters' approach, as for him media witnessing always "remains tied in some fragile way to the mortal limits of the human sensorum" and at its core is "a hint of the real" (Peters, 2009b, p. $45,48)$.

Vicarious witnessing, on the other hand, acknowledges a crucial connection between the media, namely visual media that provides visual evidence, and the audience whose role is either or both to receive and accept that evidence. Media representations, in this view, have the potential to create witness positions between people engaged in the broadcast and the imagined lives of strangers represented in, for example, a film. In this view, the broadcast or the film may become the witnessed "event" at which the audience is copresent in time and coextensive in space (Frosh, 2009, p. 52). Thus, bearing vicarious witness is an act performed not so much by a witness but by a witnessing text: "It is the witnessing text, which creates presence at the event, which produces experience out of discourse" (Frosh, 2009 p. 60). 


\section{Witnessing on YouTube}

One of the central figures arguing for the cultural relevance of vicarious witnessing and the role of audiovisual media (namely television) is John Ellis. In his book Seeing Things, Ellis (2000) maintains:

Photography, cinema and television have confronted us with much more about the wider world that previous generations had encountered. They have done so through a particular form of representation that brings with it a sense of powerless knowledge and complicit with what we see. The essence of this sense of witness is that "we cannot say that we do not know". Television has brought this sense into the home, and intensified it with its pervasive sense of liveness and intimacy.

What follows is that people who watch global news, whether as a news bulletin or an Internet stream, are entwined with the witnessing of the events of their time. To listen and watch, to hear and see, the account of an individual "directly" or “live" on a TV set or laptop implies a powerful interpersonal relationship (Ellis, 2009, p. 73,75). This assumes the adoption of the sense of responsibility; a topic I wish to return to at the end of the chapter.

Today, with the spread of the Internet and social networking sites, such as YouTube, new modalities of digital witnessing have emerged. As an audiovisual medium, YouTube can best be described as a worldwide video service. Established in 2005 , it is built on moving images, sounds, texts and remixes of these elements. In 
more technical terms, YouTube has four basic traits. First, it is a technology providing numerous channels of digital information production and sharing. Second, it is regulated and moderated privately as well as commercially (YouTube is owned by Google) and is operated by a heterogeneous group of professionals, semiprofessionals, and amateurs. Third, YouTube charges users to "broadcast yourself," which can include any kind of information. Fourth, it is characterized by global audiences dispersed in different Internet access locations (cf. Katz, 2009, p. 9). Moreover, Tolson (2010, p. 285) considers that the differences between "conventional television", as he calls it, and YouTube, also described as post-television, can be distinguished in a table:

\section{Conventional television}

Centered (in a studio)

Hierarchy of discourse

Institutional voice

Transmitted programs

Distinctive class of "media people" Ordinary people as celebrities and

Construction of otherness

Delegated gazing experts

\section{YouTube}

Decentered (in a network)

System of linkages

Individual voices

Accessed postings

"Broadcast yourself"

User navigation

The most distinct feature of YouTube witnessing is digital visuality, especially the moving image. In this sense, YouTube shares many similarities with “conventional television". However, unlike conventional television, YouTube invites authors and viewers to participate in the digital process of witnessing on a new scale, 
thus establishing novel connections between the witnessing agents, testimonials and audiences receiving and accepting these testimonies. YouTube encourages audiences, or rather, users, to comment on the evidence and testimonial materials and to share those materials via its channels. Besides the opportunity to publish and comment on witnessing videos, YouTube also offers a diverse and constantly growing selection of ways in which YouTube account owners - whether professional or amateur, can participate in disseminating witness materials: videos as witnessing representations can be shared through different social media platforms, such as Facebook or Twitter, and users can respond to them. These digital witnessing pieces can also be embedded into other websites, declared offensive, suggested to other viewers of similar videos, or subscribed to through one's own channel, thus creating new networks of mediated digital witnessing. All in all, YouTube's participatory culture - to use Burgess and Green's (2009) terms - is closely linked to the cycling and recycling of testimonials and participants, remediation, or rather premediation, as Richard Grusin (2009, p. $63-$ 64) characterizes YouTube. The idea of sharing witnesses is found in the typical "share it!" slogan of YouTube, which thus links participants to the chain of circulation of digital witnessing by "the intensification and multiplication of technical and social media networks" (Grusin, 2009, p. 63).

To summarize, YouTube offers the viewer a myriad of witness paths to follow. Instead of one dominant public sphere for media witnessing, YouTube is filled with numerous digital "little public spheres" from which anyone can choose their own (see Marcinkowski, 2008). To follow Grusin's (2009, p. 66) line of argument:

Unlike the network television of the 1950s through the 1970s (whether private or government sponsored), which aimed at producing a 
convergence of a mass audience of sufficient scale at a particular place and a particular time, YouTube produces a divergence of audience and message, temporally and territorially fostering multiple points of view rather than the small number of viewpoints represented by broadcast television. YouTube not only functions as a 24/7, global archive of mainly user-created video content, but it also serves as an archive of affective moments of formations, much as television has done for decades.

The ephemeral and vernacular character of YouTube, which dissolves media witnessing into numerous encounters between different digital witnessing agents, witnessing texts and witnessing audiences, compels us to rethink the notion of vicarious media witnessing introduced by Ashuri and Pinchevski (2009) on a new scale. Issues such as "authenticity", "authority", "truth" and "intimacy", as well as "responsibility" and "resistance" characteristically associated with media witnessing, call for further elaboration when discussed in the context of this emerging culture of digital witnessing.

\section{Witnessing in, by and through the video "For our Son"}

The video For our son was uploaded onto YouTube on 8 October 2008. It is three minutes and 22 seconds long and it is a composition of still and moving pictures accompanied by music. The description attached to the video says "My Son." When I first watched the video (16 September 2011), the video had received 746 clicks that indicated "liking" the video and 143 "disliking" it. The total number of views was 125,752. At the time of writing this piece, in March 2017, the total number of views 
had increased to 287,925 . The last comments on the video had been written a month previously. This indicates that the video has received rather modest, but steady public interest on YouTube since its publication. (For the sake of comparison, the most popular videos on YouTube gain billions of viewers. PSY Gangdam Style music video first launched in 2012 and it holds one of the most popular video titles on YouTube's history with over 2.7 billions views in 2017.)

In its three minutes, the video tells the life story (18 years) of the school shooter Pekka-Eric Auvinen. As a witness representation, For our son consists of several elements: still and moving images and music. Most of the images in the video are still pictures, most likely portraits from the Auvinen family album. The photographs show Pekka-Eric as a little boy growing up, having a meal in the kitchen, sitting on the porch, and playing with his war toys at the sand box. Moving from infancy to toddlerhood, boyhood, and finally the teenage years, the video starts to include pieces of clips taken and uploaded by Pekka-Eric himself. In one piece, Pekka-Eric is nodding at the camera wearing a t-shirt that states, "humanity is overrated". This visual material, massively disseminated in the Finnish mainstream media and social networking sites after the Jokela shootings, made the killer well known to a large Finnish audience. The video turns back to show a road, possibly the road that leads from the Auvinen home to the crime scene. The video clip For our son ends with a picture of Pekka-Eric's tombstone. The still image shows an engraving of two reindeer in the forest, Pekka-Eric's name, and the years of his birth and death.

To begin with, the issue of who constitutes a witnessing agent, that is, the question of agency in digital YouTube witnessing, is complicated. On YouTube videos in general, the question of either or both authorship and agency, who has made 
the video and who has a voice in the video, is anything but simple and straightforward. In case of so-called ordinary users, authors typically hide behind usernames and one author may have several usernames on different channels, or they may change those names over the course of time. The username attached to this particular video, For our son, is "finnbluus". This username also has a channel on YouTube. The channel, started on 8 October 2008 had 186 subscribers and 321,657 views in 2017 . The channel has a link on a website created by a username "bigpapaauvinen."1 The site portrays a picture that greatly resembles Pekka-Eric Auvinen's father. Interestingly enough, it is the other media that provide the evidence that allows this connection to be made. The national TV and newspapers interviewed the father and mother of the shooter after the attack, which made them momentary public figures. Based on the evidence described above, there is reason to postulate that the person behind the username "finnbluus" is almost certainly the father of the Jokela school shooter. The reasoning here is further supported by the written testimony attached to the video, which states:

I dont accept schoolshootings. I dont promote violence. I have right to do my grief process in peace. This video, For Our Son, is my way to process my grief.

This written testimony offers one important context for the video as a piece of witness. It explicitly states that the person behind this testimony (the father) does not approve of the school shootings, but defends his right to grieve the loss of his son publicly. The video does not openly tell the viewer why the father chose YouTube as

\footnotetext{
${ }^{1}$ http://members.soundclick.com/bigpapa...
} 
a medium for his witness or why he wants to give his testimony publicly in this particular arena.

However, if we look at the shootings as a media event, we may gain new insight. It is significant to acknowledge that the Jokela school shootings became a massive media event in Finland. Immediately after the rampage shootings, the mainstream news media fired their engines and went into disaster marathon mode, to use Liebes and Blondheim's (2005) term. In fact, the event was also premediated - it had media created about it before it actually happened (see Grusin, 2009). Pekka-Eric, the shooter, had been actively producing material for the event to come. Pekka-Eric had his own YouTube channel in which he proclaimed his philosophy of misanthropy. Before committing his crime, Pekka-Eric had uploaded a media package onto YouTube in which he announced the actions he would undertake in the coming hours. After the massacre, the mainstream audiovisual news media, in line with many active users of social media, started to circulate Pekka-Eric's material before the authorities removed it. As is typical on YouTube, despite this removal, enough users had already downloaded this material to their own computers, so that it was later uploaded again in different contexts. It is, therefore, no exaggeration to say that YouTube, like other media, was transformed into a mediated crime scene for the Jokela school shootings long before the shooter's father made his video. From this perspective, it should not surprise us that YouTube, as a platform and scene, was where the father particularly wanted his voice heard and his testimony to be received and accepted. In the world of mediated reality of school shootings, we may also infer that YouTube is given particular status as an arena of authenticity followed by amateur authority, which is not controllable by the professional mainstream media and their production machinery (see Sumiala \& Tikka, 2011.) 
It is not the father alone who bears witness to the loss of his son. We may claim that, by making and sharing this video in public, on YouTube, the father converts the video itself into a witness-bearing piece. Consequently, the video itself begins to bears witness as well. This is the issue of witnessing representation. To follow Frosh (2009, p. 60), "It is the witnessing text which creates presence at the event, which produces experience out of discourse". The video "transports us there" (Frosh, 2009, p. 60); it takes us back to the event on 7 November 2007 through the witnessing agency of the father. It is the father's experience in the video that suggests a personal transportation of the viewer into the world of the event (Frosh, 2009, p. $65)$.

One of the crucial elements in the video as a witnessing representation is the music played in the background. The song is "It is a long road," which is the theme song for Rambo I, also called "First Blood". The fact that the father chooses to associate the life and death of his son with the fate of Rambo, played by Sylvester Stallone, one of the classic masculine fighter-figures created by Hollywood since the 1980s, generates a disturbing association and makes one ask new questions about the nature of the mediated testimony in For our son. What is the video bearing witness about? Is it offering a testimony of a desperate hero or a cornered animal fighting for his life? The lyrics of the song tell about loneliness, battle and desperation. "It is a long road, when you are on your own and it hurts when they tear your dreams apart" these are the first words of the song, which was written by Dan Hill.

On YouTube it is easy to find videos on Rambo I. In some of them, the composition of the video is very reminiscent of that of For our son. Still images of Rambo change one after another, just like in the visual biography of the Jokela killer. It is difficult to avoid the association, such that the video, as a witness-bearing piece 
seen through the eyes of the father, is a testimony of a lonely and desperate fighter, disappointed, cornered and hurt by the world, which eventually leads to his selfdestruction. What the video does not explicitly address is the son as the murderer of innocent people. The documentation is weak and allusive in this sense. The visual association between the shooter and the killings is made mainly through the visual portrayal of the video clips made by the shooter himself. However, to recognize this material is a matter of contextual knowledge. The audience must already be familiar with the media event to make this connection in the video. As viewers, we are not only transported to Jokela, the site of the crime scene, but to the world of mediated reality in which the mediatization of the shootings material makes us part of the event, as if we had really been there at the school.

Finally, there is also the issue of a witnessing audience. An important issue to address in this context is the question of the constitution of "us" as an audience. Who are "we" in this context of watching the video?

In addition, we need to consider the responsibilities embedded in the practice of watching the video as a witness-bearing piece. On the one hand, the viewer witnesses the pain of the father. The father was there. He raised his son, saw him eat, sleep and play, and eventually witnessed his death. To watch the video is to participate in the suffering of the father. Boltanski (1999) calls this act distant suffering, i.e., to take part in someone's suffering via media, at a distance. However, for mediated compassion to evolve through an ethical relationship between the witnessing agent and the onlooker, the suffering needs to be recognized by the viewer. This is about the ethics of recognition and the sense of responsibility growing out of this moment of recognition, which we need to discuss here (Chouliaraki, 2011; cf. also Sumiala-Seppänen, 2008, p. 49-50). 
The sense of responsibility refers to the demand imposed by the father to be seen as an agent with the status of a suffering person (a victim), a status to be acknowledged by others watching the video. However, who counts as a victim is a complex issue in this context. A moral stand that perceives the father rather as a victimizer is also available for the audience to take. The spectacular publicity offered by the media for the killer, though post-mortem, could well support this type of moral claim.

Witnessing, Peters (2009b, p. 50) claims, suggests a morally justified individual who speaks out against an unjust power: to witness means to be on the right side. From this perspective, the digital witness given by the father is a contested matter. We may also argue that the father's claim for the right to give his testimony in making the video is to resist those given media categorizations that label witnesses and witnessing acts as morally legitimate or illegitimate positions. As the father claims on his YouTube account: "I have right to do my grief process in peace. This video, For Our Son, is my way to process my grief."

The role of YouTube as a mediator becomes even more significant in this context, as it promises to offer a digital platform for all willing to give their testimony without the moral prejudgment or gatekeeping of the mainstream media. Moreover, on YouTube we may not only watch, but we may also participate in the suffering of the father by utilizing the features offered by YouTube and other social networking sites. We may share the video For our son with our friends on Facebook or elsewhere, or we may comment on it, send our condolences by writing a post, thereby recognizing the identity of the father. By the same token, we may also exercise our right to deny his identity as a suffering person, a victim, by ignoring him or refusing to give him that role. In this sense, the reception of the witness may be highly 
ambivalent - accepted and rejected at the same time, depending on the position taken by the viewer.

At the time of writing this chapter in March 2017, the latest posting to this video was posted only a month ago. As a witness-bearing piece, the video sent out into the world of YouTube has the ability to establish new types of relationships between the father - as a person who has been "there" - and those of us who watch him, but also among those people participating in this distant suffering by watching the video.

By watching the video, we are all invited to bear digital witness to the event itself and to its mediatization (see also Sumiala, 2013). Nonetheless, it should be acknowledged that on YouTube no universal position for the viewer is available. Instead, our positions as viewers, as Peters (2009a, 2009b) reminds us, are greatly dependent upon matters related to time and space. Were we "there" in the town, at that school, when the shootings took place? Do we know any of the people involved in or attached to the crime? For those of us who were following the shootings as they emerged as a live media event on our TV screens, online news and the Internet, we may recognize certain elements in the father's witness, while others may not. Those of us who recognize the shooter as we watch the video and make the connection after having watched the killer's videos after the crimes, we have been there, in a sense: we have met the killer through his videos, though for most of us this encounter was only post-mortem. What we are witnessing, then, is not so much what happened at the school, but rather what happened in the media. Thus, here, the line between the reality "out there" and the reality mediated to us through our technical devices becomes vague. The association created between the Jokela killer and Rambo only fosters the hyperrealist effect, to use Baudrillard's (1988) term, in this mediatized digital witness. 


\section{Agony at a distance?}

Scannel (2004) considers that the moral point of the witnessing texts is, first and foremost, to make us as viewers care about the lives of others (see Frosh, 2009, p. 66). This is a profound moral claim, and calls for a need to take responsibility for one's witnessing actions. To follow the point made by Ellis (2000), those of us who watched the media event during and after the shootings from our TV screens and laptops cannot say we did not know. We know about the suffering of the father and the rest of the family, the survivors, the victims and their families. Yet the question remains: what does it mean to us?

Boltanski (1999, p. 62) reminds us that the process of identification - taking part in distant suffering, recognizing the identity of the father as a suffering individual, a victim of the crime committed by his son, is affected by the length of the mediated chain that is established between the spectator and the one who is suffering. In Boltanski's view, the situation becomes more and more delicate as the distance between the spectator and the suffering person becomes greater (Boltanski, 1999, p. 62). This may be particularly true in the era of television and mass communication. In the present era of digital networking sites like YouTube, our positions as bystanders or "children of mass society," as Ellis (2000) puts it, become contested in new ways. This is because of the interactivity embedded in YouTube. When we watch the video made by the father, we are no longer one of the masses, no longer mundane witnesses, to use another term coined by Ellis $(2009$, p. 73$)$, but rather active participants in this digital witnessing event. We may take several positions. The truth may be an issue; we may be skeptical about the truth-value of the father's testimony, or we may deny 
the right of the father to bear witness, but passivity is a difficult position to maintain. Therefore, to bear witness by watching the video is not an inattentive action.

This is not intimacy at a distance (see Frosh, 2009, p. 66). To watch the video, we have to take a position. We become involved and, hence, responsible over the type of relationship we establish with the act of witnessing. We choose the video by clicking on it and by doing so we become morally engaged in what we see. We lose a haven of passivity. Every time we watch the video, our action is made visible by a counter near the video. We are invited to share the testimony, to comment on it, even to share and circulate it. Thus, I argue, in this highly mediatized event of digital witnessing (cf. Sumiala, 2013), new kinds of digital intimacies are established between the father, the video and us as witnessing agents. On YouTube there is no escape from this.

Following Lilie Chouliaraki's (2011, p. 364) work, we may think about the question of moral responsibility in this type of digital witnessing and look at it in the framework of "agony" and "proper distance". These are the two concepts Chouliaraki borrows from Arendt (agony) (1990 [1958]) and Roger Silverstone (proper distance) (2004). The critical element in the moral responsibility thought of as agony is the recognition of the very asymmetry of power between the onlooker (the witnessing agent) and the suffering individual (the object of witnessing) - the distant spectator and the father in this case. To think about this relationship as agony is to acknowledge that the sense of pain and torment affects both parties: the viewer and the suffering other, but in different ways. The agony of the viewer arises from the awareness of the irreversible imbalance between their position and the position of the suffering other. The agony of the suffering other grows out of the loss (in this case of the son) and a need to cry this out to the world. However, pain and anguish is not the only attribute 
in digital witnessing, a "proper distance" between the two witnessing agents is also required. The viewer of the suffering other cannot overcome the very asymmetry of power, and any attempt to try to deny or diminish it is destined to fail. In addition, to widen the distance too much may also cause failure in the act of digital witnessing. We may end up falling into a trap of voyeuristic commodification by gazing at the suffering of the other in the digital media. This scenario threatens to reduce digital witnessing to an empty spectacle (see Chouliaraki 2011). Hence, agony at a distance is a position we should be invited to take as we re-think our ethical relationships with those witnessing their suffering on today's digital screens. 


\section{References}

Arendt, H. (1990/1958). The Human Condition. Chicago, IL: University of Chicago Press.

Ashuri, T. \& Pinchevski, A. (2009). Witnessing as a field. In P. Frosh \& A. Pinchevski (Eds.), Media witnessing: Testimony in the age of mass communication (pp. 133-157). Houndmills: Palgrave Macmillan.

Baudrillard, J. (1988). Selected writings. Cambridge: Polity Press.

Boltanski, L. (1999). Distant suffering: Morality, media and politics. Cambridge: Cambridge University Press.

Burgess, J. \& Green, J. (2009). YouTube: Online Video and Participatory Culture. Cambridge: Polity Press.

Chouliaraki, L. (2010). Ordinary witnessing in post-television news: Towards a new moral imagination. Critical Discourse Studies, 7(4), 305-319.

Chouliaraki, L. (2011). "Improper distance": towards a critical account of solidarity as irony. International Journal of Cultural Studies, 14(4), 363-381.

Ellis, J. (2009). Mundane witness. In P. Frosh \& A. Pinchevski (Eds.), Media witnessing: Testimony in the age of mass communication (pp. 73-88). Houndmills: Palgrave Macmillan.

Ellis, J. (2000). Seeing things: Television in the age of uncertainty. London: I.B. Tauris.

Frosh, P. (2009). Telling presences: Witnessing, mass media, and the imagined lives of strangers. In P. Frosh \& A. Pinchevski (Eds.), Media witnessing: Testimony in the age of mass communication (pp. 49-72). Houndmills: Palgrave Macmillan. 
Frosh, P. \& Pinchevski, A. (2009). Introduction. Why media witnessing? Why now? In P. Frosh \& A. Pinchevski (Eds.), Media witnessing: Testimony in the age of mass communication (pp. 1-19). Houndmills: Palgrave Macmillan.

Grusin, R. (2009). YouTube at the end of new media. In P. Snickars \& P. Vonderau (Eds.), The YouTube reader (pp. 60-67). Stockholm: National Library of Sweden.

Jenkins, H. (2006). Convergence Culture: Where Old and New Media Collide. New York and London: New York University Press.

Katz, E. (2009). The end of television. The ANNALS of the American Academy of Political and Social Science, September 625, 6-18.

Katz, E. \& Liebes, T. (2007). No more peace! How disaster, terror and war have upstaged media events. International Journal of Communication, 1, 157-166.

Liebes, T. \& Blondheim, M. (2005). Myths to the rescue: How live television intervenes in history. In E. Rothenbuhler \& M. Coman (Eds.), Media anthropology (pp. 188-198). Thousand Oaks: Sage.

Marcinkowski, F. (2008). Public sphere, fragmentation of. In W. Donsbach (Ed.), The international encyclopedia of communication. Blackwell Publishing, Blackwell Reference Online. Available at:

http://www.communicationencyclopedia.com/subscriber/tocnode?id=g978140 5131995_chunk_g978140513199521_ss138-1 (accessed 1 April 2017).

Ong, J. O. (2014) "Witnessing" or "Mediating" Distant Suffering? Ethical Questions across Moments of Text, Production, and Reception. Television \& New Media, 15(3), 179-196. 
Peters, J.D. (2009a/ 2001). Witnessing. In P. Frosh \& A. Pinchevski (eds.), Media witnessing: Testimony in the age of mass communication (pp. 23-41). Houndmills: Palgrave Macmillan.

Peters, J.D. (2009b). An afterword: Torchlight red on sweaty faces. In P. Frosh \& A. Pinchevski (Eds.), Media witnessing: Testimony in the age of mass communication (pp. 42-48). Houndmills: Palgrave Macmillan.

Rothenbuhler, E. (2010). Media events in the age of terrorism and the Internet. The Romanian Review of Journalism and Communication, V(2), 34-41.

Scannell, P. (2004). What reality has misfortune? Media, Culture \& Society, 7(26), $573-584$.

Scannell, P. (2001). Editorial. Media, Culture \& Society, 23(6), 699-705.

Silverstone, R. (2004). Proper distance: towards an ethics for cyberspace. In: G.

Liestol, A. Morrisn \& T. Rasmussen T (Eds.), Innovations (pp. 469-490). Cambridge, MA: The MIT Press.

Sumiala, J. (2013). Media and Ritual. Death, Community and Everday Life. London: Routledge.

Sumiala, J. \& Tikka, M. (2010). "Web First" to death the media logic of the school shootings in the era of uncertainty. Nordicom Review, 31, 17-29.

Sumiala, J. \& Tikka, M. (2011). Imagining globalised fears: School shooting videos and circulation of violence on YouTube. Social Anthropology/Anthropologie sociale, 19(3), 254-267.

Sumiala-Seppänen, J. (2008). Circulation. In D. Morgan (Ed.), Keywords in religion, media, and culture (pp. 44-55). London: Routledge.

Thomas, G. (2009). Witness as a cultural form of communication: Historical roots, structural dynamics, and current appearances. In P. Frosh \& A. Pinchevski 
(Eds.), Media witnessing: Testimony in the age of mass communication (pp.

89-111). Houndmills: Palgrave Macmillan.

Tolson, A. (2010). A new authenticity? Communicative practices on YouTube. Critical Discourse Studies, 7(4), 277-289.

Author: Johanna Sumiala, Dr. Associate Professor (Docent) University Lecturer Department of Social Research/ Media and Communication Studies

P.O. Box 54, 00014 University of Helsinki johanna.sumiala@helsinki.fi 